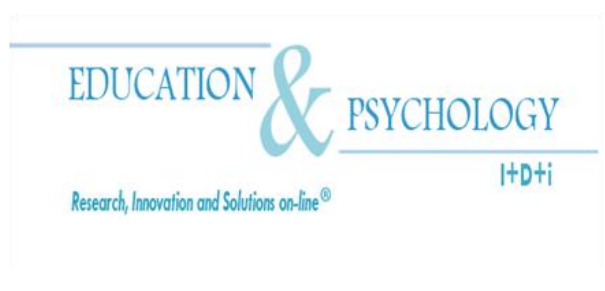

\title{
Dissatisfaction and Engagement as Motivators of Conceptual Change in a Naturalistic Internet-based Search about HPV
}

\section{Jonathan C. Hilpert ${ }^{1}$, Sarah K. Brem ${ }^{2}$}

${ }^{1}$ Assistant Professor, Georgia Southern University, Statesboro, GA

${ }^{2}$ Associate Professor, Arizona State University, Tempe, AZ

\section{United States of America}

Correspondence: Jonathan C. Hilpert. Department of Curriculum, Foundations, and Reading, Georgia Southern University; P.O. Box 8144; Statesboro, GA 30460-8144. USA; E-mail: jhilpert@ georgiasouthern.edu

(C) Education \& Psychology I+D+i and Editorial EOS (Spain) 


\begin{abstract}
Introduction. Although studies of peoples' knowledge and beliefs about Human Papillomavirus have provided good information to the medical community, few, if any, have addressed how young people construct an understanding of the virus in realistic contexts. This is problematic because increasingly people are turning to the internet for health information before talking with doctors. To address this gap in the literature, we asked participants to conduct an unguided internet search for information about human papillomavirus.
\end{abstract}

Method. We designed a longitudinal study based on the Conceptual Restructuring of Knowledge Model (CRKM), a cognitive model for conceptual change. Using multiple statistical techniques, we found evidence for key characteristics of the CRKM, including the role of dissatisfaction and engagement during conceptual change.

Results. Using multiple statistical techniques, we found evidence for key characteristics of the CRKM, including the role of dissatisfaction and engagement during conceptual change. Additionally, although average performance on the knowledge assessment increased by $32 \%$, we found that important misconceptions regarding HPV were persistent after the search.

Discussion and Conclusion. Misconceptions appear to stem from participants failing to alter their knowledge structures regarding the mechanisms of transmission, the diversity of HPV genotypes, and the relationship between virus genotypes and the effect a virus has on its host.

Keywords: conceptual change, engagement, motivation, HPV

Received: 04/16/13 Initial acceptance: 05/21/13 Final acceptance: 07/24/13 


\section{La Insatisfacción y la Implicación Motivan el Cambio Conceptual en una Búsqueda Naturalista de Internet sobre el VPH}

\section{Resumen}

Introducción. Aunque los estudios de conocimientos y creencias sobre el virus del papiloma humano han proporcionado buena información a la comunidad médica, pocos estudios, aunque sí existe alguno, han abordado cómo los jóvenes pueden construir una comprensión del virus en contextos realistas. Esto es problemático porque cada vez más personas recurren a internet para obtener información de la salud antes de hablar con los médicos. Para hacer frente a esta laguna en la literatura, se pidió a los participantes a realizar una búsqueda libre de internet para obtener información sobre el virus del papiloma humano

Método. Diseñamos un estudio longitudinal basado en el Modelo de Reestructuración Conceptual del Conocimiento (CRKM), un modelo cognitivo para el cambio conceptual. Usando varias técnicas estadísticas, encontramos evidencia de las características clave de la CRKM, incluyendo el papel de insatisfacción y compromiso durante el cambio conceptual.

Resultados. Usando varias técnicas estadísticas, encontramos evidencia de las características clave de la CRKM, incluyendo el papel de insatisfacción y compromiso durante el cambio conceptual. Además, aunque el rendimiento promedio en la evaluación de conocimiento aumentó $32 \%$, se encontró que importantes conceptos erróneos sobre el VPH persisten después de la búsqueda.

Discusión y conclusión. Las ideas falsas de los participantes no parecen alterar las estructuras de conocimiento sobre los mecanismos de transmisión, la diversidad de los genotipos HPV, y de la relación entre el virus los genotipos y el efecto que un virus hace en su huésped.

Las palabras clave: cambio conceptual, compromiso, motivación, el virus del papiloma humano. 


\section{Introduction}

Human Papillomavirus (HPV) is a common Sexually Transmitted Infection (STI) (Dunne et al., 2011) that has been widely studied by the medical community. Because vaccination against the virus has become available in the last decade, many recent studies have examined beliefs about vaccinations, including perceived risks and costs, media coverage, socio-economic differences, and so on (e.g. Darden, et al., 2013; Hilton, et al., 2010; Liau, Stupiansky, Rosenthal, \& Zimet, 2012; Polonijo \& Carpiano, 2013). One notable focus of these studies is on parents (Mays, Sturm, \& Zimet, 2004; Reiter et al., 2009; Zimet et al, 2005). Because vaccination is recommended for adolescent girls, it is assumed that parents play an integral role in vaccination decisions (Brewer \& Fazekas, 2007). Other studies, have examined knowledge and beliefs about the virus itself, including symptoms, tests, infection rates, and other characteristics (e.g. Gerend \& Magloire, 2008; Gerhardt et al., 2000; Holcomb, Bailey, Crawford \& Ruffin, 2004; Mays, et al., 2000). Studies of this persuasion provide a range of evidence about HPV knowledge useful to many in the medical community. However, neither of these strands in HPV research provides information about how young people learn about HPV on their own. Despite widespread acknowledgement that more and more people are using the internet to research health information before talking with doctors (Pew, 2013), few studies, if any, have examined how young adults construct knowledge of the virus in situ, or in a realistic setting that circumscribes authentic parameters. The purpose of this study was to examine knowledge construction about HPV in a sample of young adults during an internet search about the virus. Borrowing from the conceptual change literature (Dole \& Sinatra, 1998), as well as information seeking research (Pirolli, 2007), we designed a study to examine how young adults might learn about HPV.

\section{Conceptual Change}

Conceptual change has long been a topic of interest amongst psychologists and science educators. It is an essential tool for moving learners from their naïve theories of the world (Duit \& Treagust, 2003; Pintrich, Marx, \& Boyle, 1993; Sinatra, 2005) to more scientifically accurate models. It is different from other cognitive approaches, such as the health belief model (Rosenstock, 1974; Rosenstock, Strecher, \& Becker, 1988), because it examines how people organize and reorganize knowledge to gain more explanatory power. While the health belief model focuses on domain general beliefs such as efficacy, risk, and cost, conceptual 
change models focus on the mechanisms and structure of knowledge representation and change.

The early work on conceptual change focused on identifying knowledge structures that would lead a learner to behave in a certain way, and examining how these structures could be transformed through differentiation (e.g. Smith, Snir\&Grosslight, 1992) or ontological shifts (e.g. Chi, 1992). While a picture emerged regarding how conceptual change might occur, left unanswered were questions regarding why a person would exert the considerable effort needed for these transformations, why they would persevere, and how they would decide to bring their efforts to a close. These remaining questions are particularly relevant to the study of HPV because little work has been conducted on how young adults might initiate a realistic search for information about HPV, how they might engage in such a task, and how accurate their knowledge might be before becoming satisfied with their efforts.

Before the rise of intentional conceptual change (Sinatra \& Pintrich, 2003), the best arguments in response to questions about why people might initiate learning came from philosophy of science (Popper, 1969; Kuhn, 1971; Thagard, 1992) and science education (Posner, Strike, Hewson\&Gertzog, 1982). In theory, these scholars argued, conceptual change could only occur if environmental factors triggered the recognition of problems in existing models, allowing the learning to consider alternative explanations. These theories were supported by a number of conceptual change studies by science education researchers (e.g., Fetherstonhaugh \& Treagust, 1992; Stofflett, 1994), but the studies used many or all of Posner et al.'s recommendations for creating an environment that supports conceptual change and thus do not tell us the effectiveness of individual factors.

The arrival of intentional conceptual change in psychology (Sinatra \& Pintrich, 2003) led researches to examine individual factors in addition to environmental factors. Proponents of this position began looking at learners not as passive entities whose mental contents could be restructured and reorganized by presenting the right prompts and stimuli, but as active participants, who bring to the task their own goals and beliefs and thus exert a strong influence on the outcome of any task designed to foster conceptual change. For example, strongly-held moral, religious, and social beliefs can significantly affect the process (e.g., Chinn \& Brewer, 1993; Evans, 2001; Mason, 2000; Sinatra, Brem, \& Evans, 2008; Sinatra \& Mason, 2008; Sinatra, Southerland, McConaughy, \& Demastes, 2003), as can affective 
resistance (Linnenbrink \& Pintrich, 2002), goal orientation (Pugh, Linnenbrink-Garcia, Koskey, Stewart \& Manzey, 2010) and other factors.

\section{Conceptual Restructuring of Knowledge Model}

Integrating these many considerations into a theory of conceptual change greatly increased the complexity of the models. One of the most complete (and the one we are using as a starting point for our work) is Dole and Sinatra's (1998) Conceptual Restructuring of Knowledge Model (CRKM). In addition to examining factors that would affect the learner's thinking about competing models, the CRKM posits a set of motivational factors that would be likely to trigger a learner to engage in the process of conceptual change: dissatisfaction, personal relevance, social context, and need for cognition. Too complex to be tested in a single study, the CRKM has been widely cited and used as a starting point for studies that examine some aspect of the CRKM or its implications. For the current study, we choose to examine dissatisfaction. Learners who perceive a greater degree of dissatisfaction are more likely to be engaged, and thus should achieve strong restructuring to account for alternative explanations.

Regarding dissatisfaction, although both the Dole and Sinatra (1998) and Posner et al. (1982) models have been extremely influential, there are few studies that actually capture whether dissatisfaction is a predictor of conceptual change. Like Dole and Sinatra (1998), and Posner and colleagues before them (1982), we operationalize dissatisfaction as something akin to cognitive conflict or dissonance where learners perceive anomalies between their existing theories and external data. Related studies, such as those using refutational texts (e.g. Guzzetti, Snyder, Glass, \& Gamas, 1993), encourage conceptual change by attempting to make learners aware of the errors and limitations in their existing model while providing an alternative. These have been somewhat successful, and, implicitly, their effect seems to require the learner become dissatisfied with their own theory, but this element is not teased out and looked at separate from other factors such as available evidence and rhetorical devices.

Furthermore, although in the CRKM dissatisfaction is posited to generate engagement (Dole \& Sinatra, 1998; Posner et. al., 1982), this link has not been empirically demonstrated. High engagement, i.e., making a large investment of time, effort, and resources, is associated with significantly better performance outcomes (Bruning, Schraw, Norby, \& Ronning, 2004; 
Schraw, 2006; Zimmerman \& Schunk, 2000). Using a longitudinal approach, we isolated dissatisfaction and engagement from the strategies used to acquire knowledge and the changes in learners' understanding. This allowed us to determine whether dissatisfaction is predictive of changes in knowledge and whether the effect of dissatisfaction is mediated by engagement. Successfully demonstrating the existence and nature of these relationships would provide solid empirical support for what has been theorized.

\section{Human Papillomavirus and the Internet}

Although much has been done in regard to HPV research in recent decades, little has been done to examine how young people construct an understanding of the virus during an internet search. Young people are increasingly turning to the internet for information, especially when they might hesitate to address the issue with an expert. A recent national poll in the United States suggests that one in three people are self-diagnosing on the internet in place of or before visiting a doctor (Pew, 2013). These unguided searches for knowledge have the potential to be very useful, but also very dangerous, depending on how well the learner can distinguish between trustworthy and untrustworthy sources of information and the accuracy of their knowledge construction. Furthermore, information foraging theory (Ellis, 1989; Pirolli, 2007; Wilson, 1999) suggests that well conducted internet searches promote high cognitive engagement (Choo, Detlor, \& Turnbull, 2000; Rodgers \& Swan, 2004; Tatabatai \& Shore, 2005), similar to the behavioral forms of engagement described by educational psychologists (Fredricks, et al., 2004) and conceptual change theorists (Dole \& Sinatra, 1998).

We decided to design a scenario that would send learners on an internet search for information about HPV. Studies have documented widespread misconceptions about STIs among adolescents and young adults (e.g. CDC, 2006; Kirby, 2007; Mathematica Policy Research, Inc., 2007), and HPV is one of the most common sexually transmitted infections (CDC, 2006) and one of the most common causes of cancer in women worldwide (Ferlay, Bray, Pisani \& Parkin, 2001). We wanted to design a study to examine how young adults might develop flaws in understanding during a typical, unguided internet search for information. As participants conducted their searches, their dissatisfaction with their current knowledge, level of engagement, and changes in knowledge were measured at intervals, allowing us to conduct several types of analyses, including the creation of growth curves regarding their knowledge to examine what elements significantly predict those curves. We 
arranged these statistical analyses in order of increasing resolution, and assigned a prediction to each. Based on existing theory, we predicted that:

a) On comparing their starting states with their status at the end of the task, participant knowledge would increase and dissatisfaction with their knowledge would decrease. This was tested using paired t-tests.

b) Next, we need to determine the relative contributions of dissatisfaction and engagement to the changes in participants' knowledge, and, particularly, whether engagement mediates the relationship between dissatisfaction and knowledge change. We conducted a cross-sectional mediational analysis using multiple regression, predicting that engagement would partially mediate the relationship; i.e., dissatisfaction would lead to engagement, which would in turn lead to knowledge gain, but dissatisfaction alone would also predict a portion of the variance.

c) We next wanted to examine the relationship between dissatisfaction, engagement and knowledge change in greater detail, and control for prior knowledge. We therefore constructed a knowledge growth curve using multiple time points to determine the trajectory of knowledge change for each participant. We predicted that both initial dissatisfaction and ongoing engagement would contribute to explaining the participants' learning from one time point to the next, even when prior knowledge was taken into account.

d) Finally, we used structural equation modeling to provide us with a second look at the relative roles of dissatisfaction, engagement and knowledge change, one that provides more information than a multiple regression. We predicted that, as before, engagement would partially mediate the relationship between dissatisfaction and knowledge change.

In addition, although not a quantitative prediction, we estimated the level and type of learning that would take place during the task. There are many different ways that scholars have tried to distinguish conceptual change from other forms of knowledge acquisition. In our view, one of the more practically useful ways to do so is similar to that suggested by Chan, Burtis and Bereiter (1997), who created a continuum of knowledge acquisition from assimilation into existing knowledge structure to a highly effortful restructuring and rooting out of flaws and inconsistencies. At the center of this continuum, there is a qualitative shift 
from knowledge being simply slotted into given knowledge structures and having to engage in knowledge restructuring to make the knowledge fit.

For example, if I have a strong understanding of the STI gonorrhea, a bacterial infection, and I encounter a novel STI, chlamydia, which is also a bacterial infection, I can use my knowledge of the former to fairly quickly and easily acquire knowledge of the latter. The similarities between the disease agents anatomy and function, the routes of transmission, infection and replication, the modes of treatment, and so forth allow me to simply add to my database. If, however, I come across HIV, my knowledge of gonorrhea will not serve me well, and would cause serious errors in my thinking until restructuring occurred. The disease agents are completely different in form and function, they have different routes of infection and replication, and are treated in entirely different ways. On the Chan et al. scale, learning about chlamydia would represent assimilation, and learning about HIV would represent knowledge building.

Adolescents and young adults are not without ideas about what STIs are, how they spread, and what to do if you get one. They have naïve, untutored theories which must be overcome to have a good understanding of HPV. Given the duration of the task, and the fact that participants had only internet searches to rely on for new information, we expected that participants would engage in some knowledge restructuring, but not demonstrate the type of conceptual change that lies at the end of Chan et al.'s continuum.

\section{Method}

\section{Participants}

The participants were college students at a large public university in the Southwestern United States; 76 participants were recruited from a large lecture course to participate in the study. Data for two of the participants needed to be removed because they did not follow the study instructions. The final sample consisted of 74 participants. The mean age for the participants was 21.73. Of the participants, $21.4 \%$ were freshman, $28.6 \%$ were sophomores, $25.7 \%$ were juniors, and $24.3 \%$ were seniors. Females comprised $66 \%$ of the participants. The ethnic breakdown of the sample was as follows: $71.4 \%$ White; $7.8 \%$ Hispanic; $3.9 \%$ Black; 2.6\% Asian; 1.3\% Pacific Islander; 5.2\% "other." The sample was representative of 
the ethnic breakdown of the University, but women were overrepresented, comprising $66 \%$ of the sample, and $52 \%$ of the students at the University.

\section{Measures}

In order to examine the relationship between dissatisfaction, engagement, and knowledge building, we used three measures, and collected additional demographics regarding the participants' personal experience of STIs.

Dissatisfaction. The Likert-scale items addressed participants' dissatisfaction with their knowledge about HPV along six dimensions of STIs that are important for understanding HPV as a potential victim and taking steps to avoid infection: incidence of infection, means of transmission, effects on the health of the infected, presenting symptoms, diagnostic tests, and means of prevention. There was one item per dimension. The internal consistency of the measure was high $(\alpha=.86)$, warranting the collapsing of the dimensions into a single composite score. Example items read, "I know how common HPV infections are." and "I know about the tests for HPV." Scores were calculated so higher scores equaled greater dissatisfaction with their knowledge of HPV.

Engagement. A person's level of engagement is determined by the time and effort, planning, and reflection they expend on a task. In terms of internet searching, there are several factors that correspond to this expenditure. To create an engagement score that draws upon all of these, we created a score by summing 4 factors $(M=15.15)$. The first, search type, was coding using the parameters defined by Ellis, Cox, and Hall (1993), which have been productively employed in a number of studies on information seeking behavior (e.g., Choo, Detlor, \& Turnbull, 2000; Pirolli, 2007; Wilson, 1999). The Ellis et al. system divides searches into informal and formal. Informal searches are relatively unstructured and limited in their usefulness, and cost little in terms of time or effort. Formal searches involve planning to obtain specific information and are structured using systematic procedures; they are expensive in terms of time and effort and they indicate some process of reflection, where participants circle back to find new information. Informal searchers were scored as 1 point, formal as 2 . The second parameter was search length, with longer searches indicating greater time and effort. These were scored in terms of the number of minutes a search lasted ( $M=28 \mathrm{~min})$. Third was the number of key word searches $(M=1.96)$, with a greater number of searches 
indicating greater engagement. The fourth and final parameter was the number of websites visited $(M=2.8)$. Gathering information from a greater number of sources requires greater time and effort, planning, and reflection for success, so higher scores suggest greater engagement.

HPV Knowledge. Participants' HPV knowledge was measured using a survey created by combining information about HPV from a number of reliable sources and measures. Content of the items and the dimensions of the scale were derived from the HPV treatment guidelines provided by the CDC (CDC, 2006); the format and design of the items was taken from the young adult version of the Sexual Health Knowledge, Attitudes, and Experiences scale from the National Survey of Adolescents and Young Adults (Hoff, Greene, \& Davis, 2003).

The items were then validated by sexual health experts at Planned Parenthood and pilot tested with a sample from the same population that was drawn upon for the primary study. Thirty five items were assessed, and sixteen items were retained as part of the final scale, which showed good reliability and validity (Authors, et al., 2010); seven items were false, nine true. Sample items read, "the human immune system often destroys HPV infections without medical treatment," and "all types of HPV can cause genital warts." Participants were asked to respond "yes" or "no" to each item; correct answers were scored as 1 point, incorrect as 0 points.

Participant responses were summed, with high scores indicating greater accuracy of participants' knowledge.

Exposure. Prior experience with HPV, either by being infected or knowing someone who has been infected, was used as a control measure in the analysis. Participants were asked whether or not anyone they know, including themselves, have ever found out they had HPV. This was a dichotomous variable.

\section{Procedures}

The task of searching the internet was meant to mimic a realistic search motivated by an ill-structured problem (Chi \& Glazer, 1985). We asked participants to consider a scenario in which a close friend had contracted HPV, and had asked for their help in gathering information about the disease. We administered all study measures, and then asked them to 
begin their search. The participants were stopped at intervals of approximately 15 minutes and administered the measure of HPV knowledge. Because the participants controlled the depth and breadth of their information gathering, we gathered between 3 and 6 measures of HPV knowledge for each participant. The engagement variables were measured using internet monitoring and did not require the participants to respond directly. After the search, the participants completed the study measures a final time.

In summary, dissatisfaction was measured at the beginning and the end of the task, knowledge was measured at the beginning, during the search, and at the end, and engagement was measured during the search.

\section{Data Analysis}

To examine the relationship between knowledge dissatisfaction, engagement, and learning we conducted a series of data analyses: 1) paired samples t-tests, 2) a cross sectional meditational analysis, 3) a longitudinal analysis, 4) a structural equation model, and 5) a lower-level examination of participant HPV knowledge after the search. Each analysis provided an additional layer to our understanding of the participant searches. By accumulating univariate, longitudinal, and multivariate evidence for the relationship among the variables, we can feel more confident about offering causal claims. The sections below explain the unique contribution of each analysis.

Paired samples $t$-tests. To test the relationship between dissatisfaction and participant learning, we conducted paired samples t-tests to determine if knowledge dissatisfaction significantly decreased during the learning task and if HPV knowledge significantly increased during the learning task. The t-tests provided preliminary evidence that justified moving on to more complicated analysis.

Cross sectional analysis. To test whether engagement plays a mediational role in the learning process, we conducted a traditional cross sectional, univariate mediational analysis, following Baron and Kenny's (1986) recommendations for examining mediational relationships among variables. We constructed a HPV knowledge difference variable by subtracting participants' HPV knowledge before the search from their HPV knowledge after the search. Then, we conducted a linear regression to examine 1) the relationship between HPV knowledge dissatisfaction and HPV knowledge difference and 2) the relationship between HPV knowledge dissatisfaction and engagement. We then used multiple regression 
to examine if the linear combination of HPV knowledge dissatisfaction and engagement predicted HPV knowledge difference. This analysis provided univariate evidence for the mediational role of engagement, and justified its position in the SEM.

Longitudinal growth curve modeling. To provide evidence that dissatisfaction and engagement predicted ongoing change in HPV knowledge building, we used growth curve modeling. We constructed a multilevel model for change (Hox, 2002; Singer \& Willett, 2003) using HLM 6.0 (Raudenbush, Bryk, Cheong, \& Congdon, 2000). Unconditional means and growth models were examined to determine if there was a significant amount of variance to model in the intercept and the rate of change in the hypothesized model. Search time in minutes was entered as the unit of time. Gender and previous exposure were used to predict variance in the intercept, to control for knowledge before the search, and HPV dissatisfaction before the search and engagement were used to predict change in HPV knowledge over time. Controlling for gender and exposure both HPV dissatisfaction and engagement were entered together. Time series data give information that allows for directional interpretation of shared variance, i.e. that the combination of dissatisfaction and engagement is likely causing knowledge to change over time when controlling for outside factors.

Structural equation modeling. We constructed a structural equation model (Byrne, 2006; Klein, 2005) to examine the multivariate, mediational relationship between knowledge dissatisfaction, engagement, and change in HPV knowledge - showing how dissatisfaction, engagement, and HPV knowledge rise and fall together. In the model, engagement was situated as a mediational variable. To account for the unequal number of observations over time, we calculated the mean number of correct responses for measurements taken during the search. This provided us with three measurements per participant: before, during, and after. Examination of the chi square test and evaluation of the CFI and RMSEA were used to judge model fit (Hu \&Benter, 1999; Byrne, 2006). We evaluated the significance of model parameters and amount of variance accounted for in HPV knowledge at the three time points. This model provided a multivariate look at the mediational role of engagement by showing how dissatisfaction and knowledge change overtime together when mediated by engagement.

Persistent misconceptions. As noted above, we expected some misconceptions to remain present after the search, as the task was too brief to be likely to bring about strong conceptual change (Dole \& Sinatra, 1998). To examine participant misconceptions after the search, we conducted paired samples t-tests between participant responses before and after the 
search on the individual items in the HPV knowledge scale. We then limited our examination to those items that showed no significant improvement during the task and to which $65 \%$ or less of the participants responded correctly the first time. This analysis provided information about what the nature of the knowledge change might have been on the Chan et al. continuum.

\section{Results}

Descriptive statistics and initial t-tests

Descriptive statistics were calculated for the HPV knowledge dissatisfaction and HPV knowledge items (see Table 1). The data met required assumptions of our statistical tests, although student responses to the HPV knowledge scale after the search were slightly negatively skewed. A correlation matrix was computed for all study variables (see Table 2). Examination of the mean number of correct responses to the HPV knowledge items showed an increase in knowledge, $t(73)=8.91 ; p<.001$, although participants averaged only around $80 \%$ at the end of the task. Examination of the HPV knowledge dissatisfaction items showed a decrease in dissatisfaction after the task, $t(70)=9.43 ; p<.001$.

Table 1. Descriptive statistics for all HPV dissatisfaction and knowledge variables

\begin{tabular}{lcccccc}
\hline & Min & Max & $M$ & $S D$ & Skew & Kurtosis \\
\hline HPVdissatA & 1.00 & 6.00 & 3.62 & 1.31 & 0.04 & -0.66 \\
HPVdissatB & 2.71 & 6.00 & 2.00 & 0.81 & -0.42 & -0.47 \\
HPVknowT1 & 1.00 & 15.00 & 9.64 & 3.22 & -0.66 & 0.46 \\
HPVknowT2 & 6.00 & 16.00 & 12.07 & 2.42 & -0.87 & 0.18 \\
HPVknowT3 & 6.00 & 16.00 & 12.73 & 2.23 & -1.11 & 0.94 \\
HPVknowDiff & -3.00 & 13.00 & 3.09 & 2.99 & 0.78 & 1.36 \\
\hline
\end{tabular}

Note. $n=74$ (except for HPVsatB where $n=70$ ); HPVdissatA= HPV knowledge dissatisfaction before; HPVdissatB = HPV knowledge dissatisfaction after; HPVKnowT1= knowledge before the search; HPVknowT $=$ average midsearch knowledge scores; HPVknowT3 = knowledge after the search; HPVknowDiff = difference between HPVknowT3 and HPVknowT1

\section{Cross sectional analysis}

Multiple regression was used to determine if engagement mediated the relationship between HPV knowledge dissatisfaction and HPV knowledge difference. Linear regression 
indicated that greater dissatisfaction led to a greater increase in knowledge during the task, $t(1,73)=5.02, p<.001$. For each unit of dissatisfaction, there was a .50 unit increase in HPV knowledge difference during the search. In addition, HPV knowledge dissatisfaction and engagement were related; greater dissatisfaction led to greater engagement during the task, $t(1,73)=2.32, p=.023$. For each unit of knowledge dissatisfaction, there was a .26 unit increase in engagement. Combining dissatisfaction and engagement into the same equation yielded a statistically significant result, $F(2,71)=15.64, p<.001 ; R^{2}=.30$, with both HPV knowledge dissatisfaction, $t(2,73)=4.396, p<.001$, and engagement, $t(2,73)=2.18, p=.03$, remaining significant predictors of change in participants' knowledge about HPV. The strength of the relationship between dissatisfaction and the change in HPV knowledge decreased with the addition of engagement, indicating partial mediation.

Table 2. Correlations among all study variables

\begin{tabular}{lcccccc}
\hline & 1. & 2. & 3. & 4. & 5. & 6. \\
\hline 1. HPVknowT1 & 1 & & & & & \\
2. HPVknowT2 & $.48^{* *}$ & 1 & & & & \\
3. HPVknowT3 & $.47 * *$ & $.79 * *$ & 1 & & & \\
4. HPVdissatA & $-.65^{* *}$ & $-.30^{*}$ & $-.26^{*}$ & 1 & & \\
5. HPVdissatB & -.18 & $-.46^{* *}$ & $-.40^{* *}$ & .16 & 1 & \\
6. Engagement & -.08 & $.27 * *$ & $.33^{* *}$ & $.20^{*}$ & .03 & 1 \\
7. HPVknowDiff & $-.78^{* *}$ & .02 & .18 & $.53 * *$ & -.08 & $.34^{* *}$ \\
\hline
\end{tabular}

Note. $n=74$ (except for HPVsatB where $n=70$ ); $=p<.05 ; * *=p<.01$; HPVdissatA = HPVknowledge Dissatisfaction before; HPVdissatB $=$ HPV knowledge dissatisfaction after; HPVKnowT1 $=$ knowledge before the search; HPVknowT2 = average midsearch knowledge scores; HPVknowT3 = knowledge after the search; HPVknowDiff = difference between HPVknowT3 and HPVknowT1

\section{Longitudinal growth curve modeling}

Longitudinal growth curve modeling (Singer \& Willett, 2003) was used to determine if HPV knowledge dissatisfaction and engagement predicted change in HPV knowledge over time. The interclass correlation coefficient indicated that $36.12 \%$ of the variance in learning about HPV was attributable to between person phenomena, suggesting that individual differences were an important factor. An unconditional growth model with number of search minutes was run to establish a baseline model for change. This model indicated that $35.33 \%$ of the variance in learning about HPV was associated with linear time. 
Gender and exposure were then entered at level 2 to control for prior knowledge regarding HPV knowledge. Both gender $(p=.002)$ and exposure $(p=.000)$ were significant predictors of variance in the intercept and resulted in a $46.0 \%$ proportional reduction in between person variance in comparison to the unconditional means model. Leaving gender and exposure in the model, HPV dissatisfaction was entered at level 2; results indicated it was a significant predictor of change in HPV knowledge $(p=.047)$. Leaving gender and exposure in the model, both HPV dissatisfaction and engagement were then entered together at level 2, and the results indicated that both were both significant predictors of change in HPV knowledge over time (see Table 3). This final model resulted in a $6.1 \%$ proportional reduction in within person variance in comparison to the unconditional growth model $[\Delta$ Deviance $(3 \mathrm{df})=123.57, \mathrm{p}<.001]$.

Table 3. Growth curve model for change

\begin{tabular}{llcccc}
\hline & & Coeff & $S E$ & t-ratio & $d f$ \\
\hline For Intercept $\beta 0$ & & & & & \\
& Intercept $\gamma 00$ & 10.39 & 1.35 & 7.98 & 71 \\
& Sex $\gamma 1$ & 1.65 & 0.50 & 3.29 & 71 \\
& Exposure 02 & -2.11 & 0.45 & -4.66 & 71 \\
For slope $\beta 1$ & & & & & \\
& Intercept $\gamma 10$ & 0.16 & 0.02 & 6.83 & 243 \\
& Engagement $\gamma 11$ & 0.00 & 0.00 & -2.34 & 243 \\
& HPVdissatisfaction $\gamma 12$ & -0.01 & 0.00 & -2.38 & 243 \\
& & & $S D$ & Variance & Chi Sq \\
\hline & & 1.42 & 2.02 & 215.01 & .000 \\
Intercept u0 & & 1.84 & 3.38 & & \\
Level-1 $r$ & & & & &
\end{tabular}

Note: $n=74 ;$ Deviance $=1012.99$;Final estimation of fixed effects with robust standard errors.

\section{Structural Equation Modeling}

Structural equation modeling (Byrne, 2006) was used to determine if the hypothesized structure of our variables fit the covariance structure of our data. Our hypothesized model produced adequate fit, $\chi^{2}(15, N=70)=153.12 .47, p=.19, \mathrm{CFI}=.98, \mathrm{RMSEA}=.08, \mathrm{SRMR}$ $=.06$ (see Figure 1). The combination of HPV knowledge at Time 1, engagement, and HPV dissatisfaction before the search accounted for $33.1 \%$ of the variance in HPV knowledge at 
Time 2. The combination of HPV knowledge at Time 2, engagement, and HPV dissatisfaction after the search accounted for $63.7 \%$ of the variance in HPV knowledge at Time 3 . In the model, the relationship between HPV knowledge dissatisfaction and HPV knowledge at both Time 2 and Time 3 was not significant when controlling for engagement and prior knowledge, again providing evidence that engagement mediates the relationship between dissatisfaction and knowledge building.

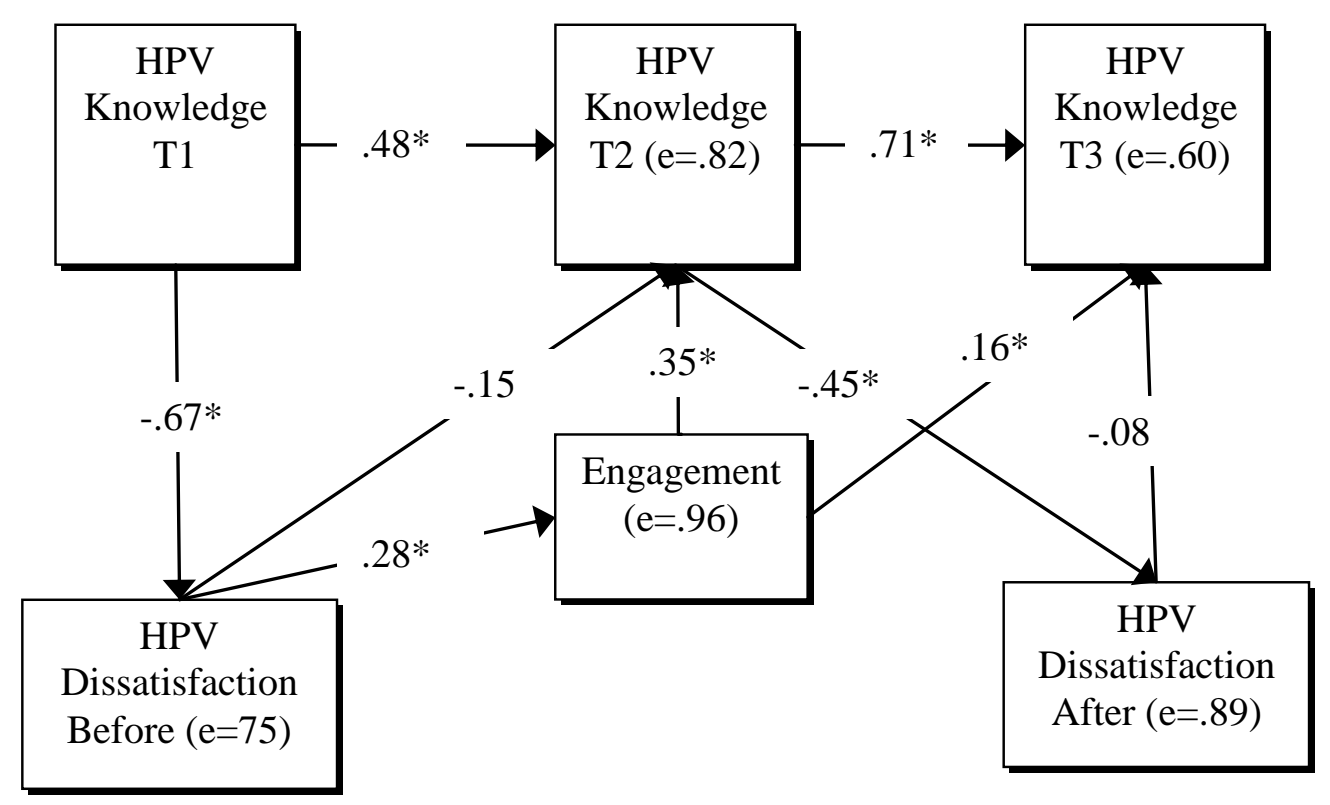

Note. $\mathrm{n}=70$; the decrease in sample size for this analysis is due to four participants who randomly experienced technical difficulty with the electronic HPV dissatisfaction scale after the search; $*=p<.05$

Figure 1. Path analytic model of change in HPV knowledge predicted by knowledge dissatisfaction and engagement.

\section{Persistent misconceptions}

Paired samples t-tests were used to isolate widespread, persistent misconception about HPV in the sample after the search. All t values were less than 1 , and less than $65 \%$ of participants correctly responded. The following items are, by these criteria, related to persistent misconceptions: 
1. "HPV is spread by sharing bodily fluids"

2. "All types of HPV can cause genital warts"

3. "Life threatening HPV infections do not have symptoms that can be seen by the carrier"

4. "Condoms are a highly effective method for preventing HPV"

\section{Discussion}

Using measures of dissatisfaction, engagement, and knowledge, as well as controls to factor out prior knowledge, we tested components of the CRKM that predict knowledge dissatisfaction is related to knowledge building, mediated by engagement. The results of several analyses supported this prediction. Knowledge increased during the search task while dissatisfaction fell in intensity. Using mediational cross-sectional analysis, the resulting multiple regression equation showed that the relationship between dissatisfaction and knowledge is linear, and partially mediated by engagement. Furthermore, a longitudinal growth curve model was consistent with the cross- sectional analysis, showing that dissatisfaction and engagement are both predictors of changes in learners' knowledge, and also controlled for prior knowledge.

The results of the structural equation model replicate these findings and provide the most complete picture. At the left side of the model, HPV knowledge before the search was related to a state of dissatisfaction, i.e., participants' metacognitive evaluation of their knowledge led to a particular level of dissatisfaction, higher levels of dissatisfaction being associated with a poorer understanding of HPV. Dissatisfaction, in turn, prompted engagement in the task. The results of knowledge building efforts varied with engagement, which was predictive of changes in knowledge during the task and in the final assessment. On the right side of the model, we see that dissatisfaction has fallen as a function of participants' success in knowledge building; the more accurate their knowledge has become during the task, the lower their dissatisfaction at the end of the task. These results provide new supporting evidence for models such as the CRKM (Dole \& Sinatra, 1998) and recommendations such as those made by Posner et al. (1982), as well as demonstrate their usefulness in context of medical social science.

However, there are several issues to keep in mind when interpreting the statistical results of the study. First, the oversampling of women in this study could have resulted in our 
underestimation of the incidence of misconceptions about HPV (addressed below), leading us to suggest caution when interpreting the descriptive statistics. However, this should not affect the relationships found between the variables, as these were not affected by controlling for gender. Second, although our sample size is appropriate for regression and growth curve modeling, it is a bit small for structural equation modeling, and could lead to inflated effect sizes and decreased global fit indices. Given that the results of the structural equation model are consistent with our other findings, we believe that the relationships demonstrated here will hold up in subsequent studies, but it may be useful to replicate the model, or one similar to it, with a larger sample. Finally, the knowledge measurements used to construct the growth curves were 15 minutes apart. We do not know what the optimal interval would be, but intervals with an insufficient distance between them can create undesirable dependencies that would underestimate the standard errors and, in turn, the p-values. We do not believe this presents a serious problem in this case, as the standard errors could increase substantially with the p-values remaining below critical values.

Despite these minor concerns, the results provide important information about how young people construct an understanding of HPV during internet searchers. This study presented learners with a rather straightforward assessment of their HPV knowledge within the context of a realistic task. Experts' understanding of HPV is sufficiently well-developed to create a clear set of undisputed declarative statements regarding some aspects of the disease, and we restricted our focus to these. As such, we were able to see quite clearly how young people improve their understanding of HPV to a certain point, one at which by in large they seem satisfied with, and then bring their efforts to a close. Yet, after the task, we were able to identify misconceptions about HPV that did persist through the end of the search. We argue our findings indicate a failure to fully grasp two key characteristics of HPV. The first is the failure to understand that HPV is transmitted through the sharing of epithelial cells. Epithelial cells are widespread; they are found, for example on the outer layers of the skin and organs. Some of these cells secrete bodily fluids, but HPV can be transmitted even when no secretions are present, if contact is made with the cells. This would explain the poor results for items \#1 and \#4 above ("HPV is transmitted through bodily fluids" and "Condoms are a highly effective method for preventing HPV"). The second issue, responsible for the poor results for items \#2 and \#3 above ("All types of HPV can cause genital warts" and "Life threatening HPV infections do not have symptoms that can be seen by the carrier") is a failure to appreciate the diversity of HPV strains. There are over 100 distinct genotypes classified as 
HPV. Depending on the genotype, HPV causes several types of cancer, genital warts, and respiratory infections, while others cause poorly understood changes to the cells they infect. This makes the development of vaccines and treatments extremely complicated, and it also seems to be an aspect of the infection with which young people may struggle.

Both of these underlying problems are good examples of inaccurate knowledge structures that will require strong restructuring to overcome. For example, understanding that STIs can be passed through other means than sexual intercourse requires reconceptualizing "sexually transmitted" to mean "primarily transmitted during sexual activity" and building a representation of transmission and infection that is much more detailed and includes such elements as the anatomy of cells and viruses, and a cellular-level understanding of how viruses replicate and what it means to be infected. Becoming aware that clinicians and researchers use one name to identify a class of viruses means creating a more complex representation of viruses, including a conceptualization of how the structure of a virus plays a role in the effect the virus has on cells, and therefore on the body. The results of this study suggest that helping patients reconceptualize these aspects of the infection may be important challenges faced by clinicians when internet educated patients walk through the door. This type of strong restructuring, or accurate knowledge building, about the complexities of the infection does not seem likely during naturalistic learning about HPV on the internet.

It is often the case though, that while experts agree certain scientific facts are more or less indisputable they are not in agreement as to what the correct position should be. For example, experts are in agreement that HPV vaccines protect against infection by certain HPV strains, that vaccines are made using the protein coat of the virus rather than the whole virus, and that vaccines are not effective against an existing HPV infection. However, there is debate over who should be vaccinated and when. For example, the Center for Disease Control recommends vaccination of girls and boys 11 and 12 years of age; the World Health Organization guidelines recommend girls between the ages of 9 and 13 be vaccinated and gives no recommendation regarding boys. And these recommendations are likely to change over time. Moreover, conservative social and political groups in the United States, who believe that vaccination will encourage risky behaviors, recommend no vaccination for anyone.

In cases like these, dissatisfaction and engagement alone will not lead to a "correct" model, even if the learner is able to identify and locate legitimate sources of information. In 
such instances, dissatisfaction should remain beyond the location of one or two legitimate sources of information, and should continue until the learner feels they have identified, at a minimum, all of the most widely-held positions. Ideally, they would also have a good sense of where the positions were consistent and inconsistent, and the factors that lead the parties to take up different positions. When it comes time for someone to adopt a position, the type of naturalistic learning we have examined maybe crucial to understanding why one choose a certain stance over another. We believe that it will be interesting to examine any differences in the way dissatisfaction and engagement affect the pursuit of information and decision making in these more complex cases. And, more generally, continued applications of the CRKM during health related learning tasks may provide additional insight into research questions where controversy and complexity make cognition a particularly salient aspect of knowledge reorganization and decision making.

\section{References}

Baron, R. M., \& Kenny, D. A. (1986). The moderator-mediator variable distinction in social psychological research: Conceptual, strategic, and statistical considerations. Journal of Personality and Social Psychology, 51(6), 1173-1182. doi: 10.1037/00223514.51.6.1173

Brewer, N. T., \& Fazekas, K. I. (2007). Predictors of HPV vaccine acceptability: A theoryinformed, systematic review. Preventative Medicine, 45, 107-114. doi: 10.1186/14712458-12-31

Bruning, R. H., Schraw, G. J., Norby, M. N., \& Ronning, R. R. (2004). Cognitive psychology and instruction $\left(4^{\text {th }}\right.$ ed.). Upper Saddle River, New Jersey: Merrill Prentice Hall.

Byrne, B. (2006). Structural Equation Modeling with EQS: Basic Concepts, Applications, and Programming. Mahwah, NJ: Lawrence Erlbaum Associates.

CDC (2006). Sexually transmitted diseases treatment guidelines, 2006. (Department of Health and Human Services Centers for Disease Control and Prevention No.RR-11). Atlanta, GA: Coordinating Centers for Health and Human Services.

Chan, C., Burtis, J., \& Bereiter, C. (1997). Knowledge building as a mediator of conflict in conceptual change. Cognition and Instruction, 15, 1-40. doi: 10.1207/s1532690xci1501_1 
Chi, M. T. H., \& Glaser, R. (1985). Problem solving ability. In R. J. Sternberg (Ed.), Human abilities: An information processing approach (pp. 227-250). New York: Freeman.

Chi, M.T.H. (1992). Conceptual change with and across ontological categories: Examples from learning and discovery in science. In R. Giere (Ed.), Cognitive models of science: Minnesota studies in the philosophy of science (pp. 129-186). Minneapolis, MN: University of Minnesota Press.

Chinn, C. A., \& Brewer, W. F. (1993). The role of anomalous data in knowledge acquisition: A theoretical framework and implications for science instruction. Review of Educational research, 63(10), 1-49. doi: 10.3102/00346543063001001

Choo, W. C., Detlor, B., \& Turnbull, D. (2000). Information seeking on the web: an integrated model of browsing and searching. First Monday, 5(2), 2000.

Darden, P. M., Thompson, D. M., Roberts, J. R., Hale, J. J., Pope, C., Naifeh, M., \& Jacobson, R. M. (2013). Reasons for not vaccinating: National immunization survey of teens, 2008-2010. Pediatrics, 131, 645-651. doi: 10.1542/peds.2012-2384

Dole, J. A. \& Sinatra, G. M. (1998). Reconceptualizing change in the cognitive construction of knowledge. Educational Psychologist, 33(2/3), 109-128. doi: 10.1080/00461520.1998.9653294

Duit, R. \& Treagust, D. G. (2003) Conceptual change: A powerful framework for improving science teaching and learning. International Journal of Science Education, 25(6), 671688. doi:10.1080/09500690305016

Dunne, E.F., Sternberg, M., Markowitz, L.E., McQuillan, G., Swan, D., Patel, S., \& Unger, E.R. (2011). Human papillomavirus (HPV) 6, 11, 16, and 18 prevalence among females in the United States-National Health and Nutrition Examination survey, 2003-2006: Opportunity to measure HPV vaccine impact? Journal of Infectious Diseases, 204, 562-565. doi: 10.1093/infdis/jir342

Ellis, D. (1989). A behavioral model for information retrieval system design. Journal of Information Science, 15, 237-247. doi: 10.1177/016555158901500406

Ellis, D. Cox, D., \& Hall, K. (1993). A comparison of the information seeking patterns of researchers in the physical and social sciences. Journal of Documentation, 49(4), 356369. doi: http://dx.doi.org/10.1108/eb026919

Evans, E. M. (2001). Cognitive and contextual factors in the emergence of diverse belief systems: Creation versus evolution. Cognitive Psychology, 42(3), 217-66. doi:10.1006/cogp.2001.0749 
Ferlay, J., Bray, F., Pisani, P., \& Parkin, D. M. (2001). Globocan 2000: cancer incidence, mortality and prevalence worldwide, version 1.0. IARC Cancer Base no. 5. Lyons, France: IARC Press.

Fetherstonhaugh, T., \& Treagust, D. F. (1992). Students' understanding of light and its properties: Teaching to engender conceptual change. Science Education, 76(6), 653672. doi: $10.1002 /$ sce. 3730760606

Gerend, M. A., \& Magloire, Z. F. (2008). Awareness, knowledge, and beliefs about human papillomavirus in a racially diverse sample of young adults. Journal of Adolescent Health, 42, 237-242. doi:10.1016/j.jadohealth.2007.08.022

Gerhardt, C. A., Pong, K., Kollar, L. M., Hillard, P. J., \& Rosenthal, S. L. (2000). Adolescents' knowledge of human papillomavirus and cervical dysplasia. Journal of Pediatric Adolescent Gynecology, 13, 15-20. http://dx.doi.org/10.1016/S10833188(99)00031-5

Guzzetti, B. J., Snyder, T. E., Glass, G. V., \& Gamas, W. S. (1993). Promoting conceptual change in science: A comparative meta-analysis of instructional interventions from reading education and science education. Reading Research Quarterly, 28, 116-161. http://www.jstor.org/stable/747886

Hilton, S., Hunt, K., Langan, M., Bedford, H., \& Petticrew, M. (2010). Newsprint media representations of the introduction of the HPV vaccination programme for cervical cancer prevention in the UK (2005-2008). Social Science \& Medicine, 70, 942-950. doi: 10.1016/j.socscimed.2009.11.027

Holcomb, B., Bailey, J. M., Crawford, K., \& Ruffin, M. T. (2004). Adults' knowledge and behaviors related to human papillomavirus infection. Journal of American Board of Family Practice, 17, 26-31. doi: 10.3122/jabfm.17.1.26

Hox, J. (2002). Multilevel analysis: Techniques and applications. Mahwah NJ: Lawrence Erlbaum Associates.

Hu, L., \& Bentler, P. M. (1999). Cutoff criteria for fit indexes in covariance structure analysis: Conventional criteria versus new alternatives. Structural Equation Modeling, 6, 1-55. doi:10.1080/10705519909540118

Kirby, D. (2007). Emerging answers: Research findings on programs to reduce teen pregnancy (summary). Washington, DC: National Campaign to Prevent Teen Pregnancy.

Kline, R. B. (2005). Principles and practice of structural equation modeling. New York, NY: The Guilford Press. 
Kuhn, T. (1970). The structure of scientific revolutions $\left(2^{\text {nd }}\right.$ ed.). Chicago: University of Chicago Press.

Liau, A., Stupiansky, N. W., Rosenthal, S. L., \& Zimet, G. D. (2012). Health beliefs and vaccine costs regarding human papillomavirus (HPV) vaccination among a U.S. sample of adult women. Preventative Medicine, 54, 277-279. http://dx.doi.org/10.1016/j.bbr.2011.03.031

Linnenbrink, E. A. \& Pintrich, P. R. (2002). Motivation as an enabler for academic success. School Psychology Review, 31(3), 313-327.

Mason, L. (2000). Role of anomalous data and epistemological beliefs in middle students' theory change on two controversial topics. European Journal of Psychology of Education, 15, 329-346. doi: 10.1007/BF03173183

Mathematica Policy Research, Inc. (2007, April). Impacts of title 5, section 510 abstinence only education programs: Final report (MPR Reference No. 8549-110). Washington, DC: Trenholm, Christopher.

Mays, R. M., Sturm, L. A., \& Zimet, G. D. (2004). Parental perspective on vaccinating children against sexually transmitted infections. Social Science \& Medicine, 58, $1405-$ 1413. http://dx.doi.org/10.1016/S0277-9536(03)00335-6

Mays, R. M., Zimet, G. D., Winston, Y., Kee, R., Dickes, J., Su, L. (2000). Human papillomavirus, genital warts, pap smears, and cervical cancer: Knowledge and beliefs of adolescent and adult women. Health Care for Women International, 5, 361-374. doi: 10.1080/07399330050082218

Ohlsson, S. (2009). Resubsumption: A possible mechanism for conceptual change and belief revision. Educational Psychologist, 44, 20-40. doi:10.1080/00461520802616267

Pew Internet and American Life Project (2013).Health Online 2013. Retrieved from http://www.pewinternet.org/Press-Releases/2013/Health-Online-2013.aspx; January 28th, 2013.

Pintrich, P. R., Marx, R. W., Boyle, R. A. (1993). Beyond cold conceptual change: The role of motivational beliefs and classroom contextual factors in the process of conceptual change. Review of Educational Research, 63, 167-199. doi: $10.3102 / 00346543063002167$

Pirolli, P. (2007). Information foraging theory: Adaptive interaction with information. New York, NY: Oxford University Press. 
Polonijo, A. N. \& Carpiano, R. M. (2013). Social inequalities in adolescent human papillomavirus (HPV) vaccination: A test of fundamental cause theory. Social Science \& Medicine, 82, 115-125. http://dx.doi.org/10.1016/j.socscimed.2012.12.020

Popper, K. (1959). The logic of scientific discovery. London: Hutchinson.

Posner, G.J., Strike, K. A., Hewson, P. W. \& Gertzog, W. A. (1982). Accommodation of a scientific conception: Toward a theory of conceptual change. Science Education, 66, 211-227. doi: 10.1002/sce.3730660207

Pugh, K. J., Linnenbrink-Garcia, L., Koskey, K. L., Stewart, V. C. \& Manzey, C. (2010). Motivation, learning, and transformative experience: A study of deep engagement in science. Science Education, 94(1), 1-28. doi: 10.1002/sce.20344

Raudenbush, S. W., Bryk, A. S., Cheong, Y. F., \& Congdon, R. T. (2000). HLM 6: Hierarchical Linear and Nonlinear Modeling. Scientific Software International, Inc.

Reiter, P. L., Brewer, N. T., Gottlieb, S. L., McRee, A. L., \& Smith, J. S. (2009). Parents health beliefs and HPV vaccination of their adolescent daughters. Social Science \& Medicine, 69, 475-480. doi: 10.1016/j.socscimed.2009.05.024

Rogers, D., \& Swan, K. (2004). Self-regulated learning and internet searching. Teachers College Record, 106, 1804-1824. http://dx.doi.org/10.1111/j.1467-9620.2004.00406.x

Rosenstock, I. M. (1974). Historical origins of the health belief model. Health Education Monographs, 2, 1-8.

Rosenstock, I. M., Strecher, V. J., \& Becker, M. H. (1988). Social learning theory and the health belief model. Health Education Quarterly, 15, 175-183. doi: $10.1177 / 109019818801500203$

Schraw, G. (2006). Knowledge: Structures and processes. In P.A. Alexander \& P. H. Winne (Eds.), Handbook of Educational Psychology (pp. 369-390). Mahwah, NJ, Lawrence Erlbaum Associates.

Sinatra, G. M. (2005). The "warming trend" in conceptual change research: The legacy of Paul R. Pintrich. Educational Psychologist. 40, 107-115. doi:10.1207/s15326985ep4002_5

Sinatra, G. M., \& Mason, L. (2008). Beyond knowledge: Learner characteristics influencing conceptual change. In S. Vosniadou (Ed.), Handbook on Conceptual Change. Mahwah, NJ: Erlbaum.

Sinatra, G. M., Brem, S. K., Evans, E. M. (2008). Changing minds? Implications of conceptual change for teaching and learning about biological evolution. Evolution Education Outreach, 1, 189-195. doi: 10.1007/s12052-008-0037-8 
Sinatra, G. M., Southerland, S. A., McConaughy, F., \& Demastes, J. (2003). Intentions and beliefs in students' understanding and acceptance of biological evolution. Journal of Research in Science Teaching, 40, 510-528. doi: 10.1002/tea.10087

Sinatra, G.M. \&Pintrich, P.R. (2003). Intentional conceptual change. Mahwah, NJ: Erlbaum

Singer, J. D. \& Willett (2003). Applied longitudinal data analysis. New York: Oxford University Press.

Smith, C., Snir, J., \& Grosslight, L. (1992).Using conceptual models to facilitate conceptual change: The case of weight-density differentiation. Cognition and Instruction, 9(3), 221-283. doi:10.1207/s1532690xci0903_3

Stofflett, R. T. (1994). The accommodation of science pedagogical knowledge: The application of conceptual change constructs to teacher education. Journal of Research in Science Teaching, 31(8), 787-810. doi: 10.1002/tea.3660310804

Tabatabai, D., \& Shore, M. (2005). How experts and novices search the web. Library and Information Science Research, 27, 222-248.

http://dx.doi.org/10.1016/j.lisr.2005.01.005

Thagard, P. (1992). Conceptual Revolutions. Princeton, NJ: Princeton University Press.

Wilson, T. D. (1999). Models in Information Behavior Research. The Journal of Documentation, 55, 249-270. doi: 10.1108/EUM0000000007145

Zimet, G. D., Perkins, S. M., Sturm, L. A., Bair, R. M., Juliar, B. E., \& Mays, R. M. (2005). Predictors of STI vaccine acceptability among parents and their adolescent children. Journal of Adolescent Health, 37, 179-186. http://dx.doi.org/10.1016/j.jadohealth.2005.06.004

Zimmerman B. J., \& Schunk, D. H. (2001). Self-regulated learning and academic achievement: Theoretical perspectives (2nd ed). Mahwah, NJ: Lawrence Erlbaum Associates. 